\title{
EL SÓCRATES JENOFONTEO COMO MAESTRO EMOCIONAL: LA ESFERA PÚBLICA EN MEM. III.7. 1-9 DESDE UNA PERSPECTIVA ARENDTIANA
}

\author{
JUAN BAUTISTA BARDI ${ }^{1}$
}

RESUMEN: En Mem. III.7.1-9 Jenofonte nos relata una conversación que habrían mantenido el joven Cármides con Sócrates. Este último buscaba convencerlo para que participara activamente en los asuntos políticos de la pólis. La reticencia de Cármides no se debía a una falta de aptitud, sino a que, incluso teniendo experiencia aconsejando a los más altos funcionarios atenienses en reuniones privadas, sentía "vergüenza" ( $\alpha i \delta \omega ́ \varsigma)$ y "miedo" ( $\varphi o ́ \beta o \varsigma)$ de manifestarse ante el pueblo.

¿Cómo explicar la variación emocional de Cármides a partir del espacio involucrado? Consideramos que, al incorporar una lectura arendtiana sobre el anterior pasaje es posible clarificar dicha interrogante. En La Condición Humana Arendt sostuvo que uno de los factores estructurantes de la sociedad ateniense era la clara delimitación entre la esfera pública y privada de la vida. La pólis tenía como nota distintiva el haber creado un "espacio de aparición" al cual sus ciudadanos ingresaban para que las acciones y discursos allí realizados fuesen conservados en la memoria colectiva. A su vez, la esfera pública "se trataba del único lugar donde los hombres podían mostrar real e invariablemente quienes eran" (2020: 52).

De allí que las emociones de Cármides -la vergüenza y el miedo a manifestarse ante el pueblo- bien puedan estar fundadas en el hecho de que en aquel contexto se ponía en juego algo que en la esfera privada estaba totalmente ausente: la construcción de su identidad como ciudadano. Lo que Cármides hiciera y dijera en la asamblea quedaría grabado en la memoria colectiva de la pólis.

Palabras clave: Jenofonte - Arendt - esfera pública - emociones.

\footnotetext{
${ }^{1}$ UBA. E-mail: juanbautistabardi@gmail.com Fecha de recepción: 21/10/2021; fecha de aceptación: 9/12/2021. DOI: https://doi.org/10.46553/sty.30.30.2021.p18-35
} 
ABSTRACT: In Mem. III.7.1-9 Xenophon introduces a conversation held between the young Charmides and Socrates. The last one was trying to convince the first one to actively participate in the political affairs of the polis. The negative of Charmides was not rooted in a lack of capacities, since he had experience advising important Athenian officials in private meetings,

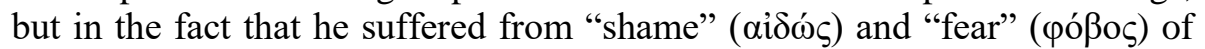
publicly showing himself to the mob.

How can the emotional variation of Charmides in relation to the public space involved be explained? I consider that, if the philosophy of Hannah Arendt is incorporated to the interpretation of the previous passage, light can be shed over this question. Particularly in The Human Condition, she claimed that one of the main characteristics of Athenian democracy was the clear demarcation between the public and the private spheres of life. The polis had been capable of creating a "space of appearance" in which its citizens entered so as their actions and speeches there performed were kept in the collective memory. Furthermore, the public realm "was the only place where men could show who they really and inexchangeably were" (1998: 41).

Therefore, Charmides emotions -the shame and fear of appearing in front of the mob- can be rooted in the fact a procedure took place in thar context which was totally absent in the private sphere: the construction of his civic identity as a citizen. What Charmides happened to do or say in the Assembly would become engraved in the collective memory of the polis.

Keywords: Xenophon - Arendt - public sphere - emotions.

\section{1) INTRODUCCIÓN: MEMORABILIA Y LA ACUSACIÓN A SÓCRATES}

Los cuatro libros que componen Memorabilia pueden considerarse uno de los intentos más vehementes de reivindicación de la figura de Sócrates por parte de alguno de sus discípulos que haya sido conservado por la tradición. Todos los pasajes allí incluidos pueden ser leídos como teniendo un mismo

Stylos. 2021; 30 (30); pp. 18-35; ISSN: 0327-8859; E-ISSN: 2683-7900 
objetivo: revertir uno de los dos aspectos de la acusación que llevó a Sócrates a la muerte, la cual es transcripta por Jenofonte al comienzo de la obra:

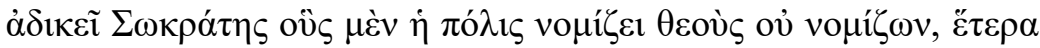

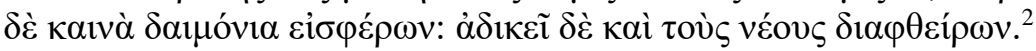

Sócrates es culpable de no reconocer los dioses que reconoce la ciudad, introduciendo, en cambio, nuevas divinidades. También es culpable de corromper a los jóvenes. ${ }^{3}$

Inmediatamente luego, Jenofonte dará comienzo a una compleja estrategia argumentativa en donde la defensa a su maestro se irá entrelazando con la exposición de sus propias doctrinas filosóficas. Es a partir de este solapamiento que postulará uno de los ejes centrales de la obra: la conducta de Sócrates -tanto sus prácticas religiosas, como el trato con sus jóvenes discípulos- no violentó las fronteras que dividían la esfera pública y privada de la vida en sociedad.

Esta clave de lectura anclada en la tensión entre "lo público" y "lo privado" es la propuesta por Vincent Azoulay para interpretar todo el corpus jenofonteo, siendo el pilar estructurante de su propuesta política. Para el helenista francés la particularidad que presenta Memorabilia es que allí Jenofonte construirá un Sócrates que “...lejos de buscar abolir la separación entre lo público y lo privado...", como bien podría haber sido una de las estrategias a adoptar, intentará demostrar que dicha distinción era "irrelevante en el contexto de una reflexión sobre el arte de mandar" (AZOULAY, 2009: 153). ${ }^{4}$ En otras palabras, buscará "neutralizar" su significado (AZOULAY, 2009: 155).

Tomando como punto de partida esta interpretación, propondré el siguiente recorrido. Primero, señalaré los pasajes de Memorabilia en donde dicha tensión es tematizada de forma explícita, para luego detenerme en uno

\footnotetext{
${ }^{2}$ Mem. I. 1.1

${ }^{3}$ Todas las traducciones del griego son propias. La edición de los textos griegos corresponde siempre a la de MARCHANT (1920).

${ }^{4}$ La traducción del francés es propia.
} 
en particular: la conversación que habría mantenido Sócrates con el joven Cármides (Mem. III. 7). La riqueza de este pasaje se funda en el hecho de que aquella tensión entre lo público y lo privado se va a ver complejizada al vincularse con el problema de la participación política y las emociones que ésta suscita. ${ }^{5}$

Ahora bien, dado que estos dos últimos aspectos no son profundizados en el análisis que Azoulay hace del pasaje, considero que, para lograr integrarlos, es necesario valernos de otras herramientas conceptuales. Recuperando la forma en la que Hannah Arendt en La Condición Humana describió la esfera pública en Atenas a partir de su concepto de "espacio de aparición" (space of appearance), intentaremos mostrar cómo aquello que se ponía en juego en la participación de Cármides en la asamblea y que condicionaba sus emociones era su misma construcción identitaria frente al resto de los ciudadanos.

\section{2) LA ESFERA PÚBLICA Y PRIVADA EN JENOFONTE: COMENTARIOS PRELIMINARES}

Antes de adentrarnos en el análisis de los pasajes seleccionados, debemos señalar que Jenofonte presentará la tensión entre aquello que hemos decidido llamar la esfera pública y privada recurriendo, principalmente, a la contraposición de dos conceptos: tò koinón, por un lado, y tò ídion, por el otro. Desde ya, esto merece una serie de advertencias.

Si bien las traducciones más autorizadas de Memorabilia tienden a optar al momento de traducir estas expresiones por "lo público" y "lo privado" respectivamente, ${ }^{6}$ dicha elección no deja de ser problemática. Siempre se debe lidiar con el riesgo de proyectar en la antigüedad clásica nuestra comprensión contemporánea sobre aquella tensión, fuertemente signada por la

\footnotetext{
${ }^{5}$ Resulta pertinente aclarar que el reciente interés mostrado por la academia en torno a las emociones en la antigüedad clásica no ha llevado a un estudio exhaustivo del corpus xenophonteum desde esta perspectiva. Ahora bien, referencias sobre Memorabilia, aunque no sobre los pasajes analizados en el presente trabajo, pueden encontrarse en KONSTAN (2006). Para un abordaje de las emociones en la Ciropedia de Jenofonte, ver TAMIOLAKI (2021).

${ }^{6}$ Nos referimos a la de Bevilacqua (2010) y la de Dorion (2011).
}

Stylos. 2021; 30 (30); pp. 18-35; ISSN: 0327-8859; E-ISSN: 2683-7900 
tradición jurídico-política moderna. Por lo que, en un intento de convivir con esta limitación, resulta útil enfatizar los significados más amplios, aunque tal vez menos técnicos, a los que remiten esa pareja conceptual, como lo es el contrapunto entre "lo comunitario" o "lo colectivo", frente a "lo particular" o "lo individual".

El segundo punto que debemos mencionar es que a veces, aunque cuantitativamente menos usual, Jenofonte reemplazará la expresión tò koinón por tò démósion, sin que se advierta, como mostraremos, un intento de marcar la pertenencia a un ámbito diferente.

Por último, Jenofonte tenderá a asociar dichos ámbitos a determinados espacios o redes de vinculación: El primero aparecerá asociado a los lugares comunes de la pólis, mientras que el segundo a los atinentes al oíkos.

\section{3) LA ASÉBEIA DE SÓCRATES ENTRE LOS SACRIFICIOS PÚBLICOS Y PRIVADOS (MEM. I. 1. 2-20)}

Hechas las debidas aclaraciones, prosigamos con el análisis del texto jenofonteo. La primera contraposición entre ambos ámbitos aparece en la primera defensa que Jenofonte hace de la alegada asébeia de su maestro. Sócrates no podría haber sido impío:

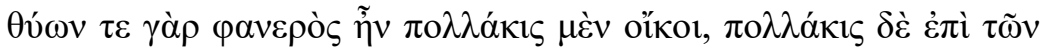

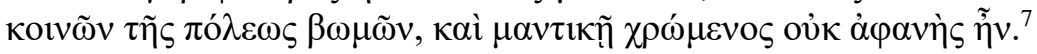

Pues a menudo se lo veía ofreciendo sacrificios, tanto en su casa, como también en los altares públicos de la ciudad, y tampoco era oculto que recurría a la adivinación.

Más adelante seguirá enfatizando esta cuestión al señalar que:

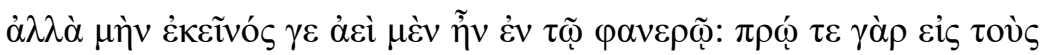

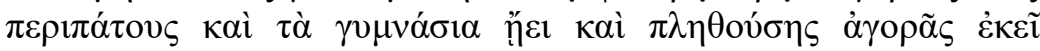

\footnotetext{
${ }^{7}$ Mem. I. 1. 2.
} 


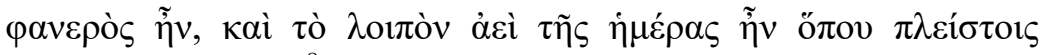

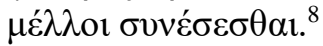

Sin embargo, él siempre estaba a la vista. Pues, a la mañana iba a los lugares de paseo y a gimnasios, y a la hora en que el Ágora se llena, allí estaba visible, y el resto del día siempre estaba allí dónde pudiera relacionarse con la mayor cantidad de personas.

Estos pasajes nos permiten ver cómo, desde un comienzo, la estrategia de Jenofonte irá oscilando de forma pendular en describir la conducta de su maestro tanto en un contexto público, el cuál es asociado de forma genérica a los espacios comunes de la pólis (altares, pórticos, gimnasios y ágora), como también en un contexto privado, el cual es asociado, en este caso, al oíkos (la casa). A su vez, se empieza a prefigurar un criterio propio que servirá para distinguir ambas esferas y sobre el cuál volveremos al final del trabajo. Resulta notable que la conducta de Sócrates está signada por la mostra-

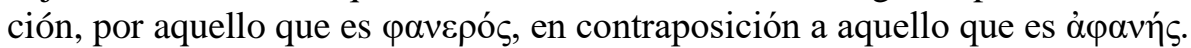
Lo que se encuentra visible, manifiesto y claro, frente a lo invisible, oculto, y secreto. Y por más que ninguna de estas características es patrimonio exclusivo de alguno de los ámbitos en tensión, si hay algo que parece caracterizar la esfera pública en la obra jenofontea es que potencia la capacidad de estar a la vista de la mayor cantidad de individuos y de maximizar las instancias para entablar vínculos intersubjetivos.

No resulta extraño que en la Apología de Sócrates Jenofonte recurra al mismo planteo:

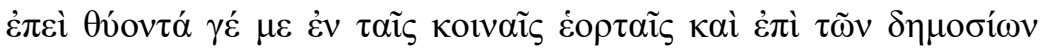

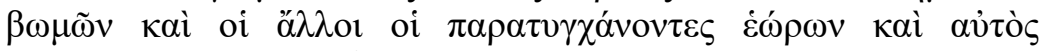

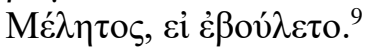

Puesto que tanto los que se encontraban presentes como el propio Meleto, si lo deseaba, podían verme cuando hacía sacrificios en las fiestas públicas y en los altares del pueblo.

\footnotetext{
${ }^{8}$ Mem. I. 1.10.
}

${ }^{9}$ Apol. 11.

Stylos. 2021; 30 (30); pp. 18-35; ISSN: 0327-8859; E-ISSN: 2683-7900 
Nuevamente aparecen temáticas idénticas, aunque conceptualizadas de una forma sutilmente diferente. En primer lugar, aquí los altares de la

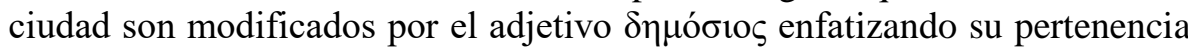
al pueblo, y no por kowvó como en Mem. I. 1.2, lo que, lejos de marcar una contradicción, confirmaría la tendencia en Jenofonte a no distinguir sustancialmente entre ambos conceptos. Por su parte, kotvó $\varsigma$ es utilizado para describir las celebraciones organizadas por la pólis, sin que se esté buscando ubicarlas en un ámbito diferente al que ocupan los altares. En segundo lugar, se vuelve sobre la idea de la visibilidad de Sócrates, aunque en este caso se recurre explícitamente al verbo óó́ (ver, mirar, observar), y no al juego

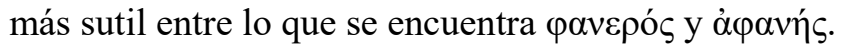

\section{4) ADMINISTRADORES DE PÓLEIS Y GOBERNANTES DE OÍKOI} (MEM. III. 4. 1-12)

En palabras de Jenofonte, el Libro III de Memorabilia presenta una serie de ejemplos de cómo Sócrates:

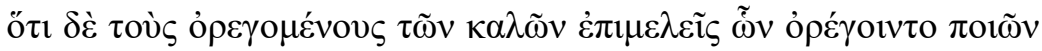

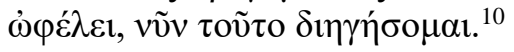

ayudaba a quienes aspiraban a conseguir distinciones, haciéndoles ejercitarse en lo que pretendían.

Por ende, todo indica que se buscará subvertir la segunda parte de la acusación mencionada al comienzo de la obra. Pero lo que nos interesa particularmente, y allí la importancia para el presente trabajo, es que aquí Jenofonte comenzará a construir de forma más clara el argumento mediante el cual "neutralizará" la distinción entre la esfera pública y privada. Esto emerge con claridad en la conversación entre Sócrates y Nicomáquides, luego de que el último retornara ofuscado de una votación en la que no logró ser

${ }^{10}$ Mem. III. 1. 1.

Stylos. 2021; 30 (30); pp. 18-35; ISSN: 0327-8859; E-ISSN: 2683-7900 
elegido estratego. Los atenienses habían optado por Antístenes, quien según Nicomáquides:

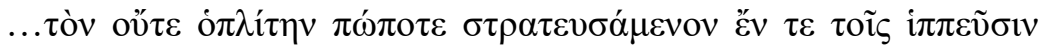

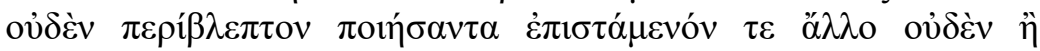
$\chi \rho \eta ́ \mu \alpha \tau \alpha \sigma \nu \lambda \lambda \varepsilon ́ \gamma \varepsilon เ v .{ }^{11}$

...ni sirvió nunca como hoplita ni hizo nada llamativo en caballería, y no sabe otra cosa que acumular dinero.

Sócrates, lejos de coincidir en su crítica, elogia las virtudes de Antístenes, porque si bien efectivamente carecía de las cualidades mencionadas,

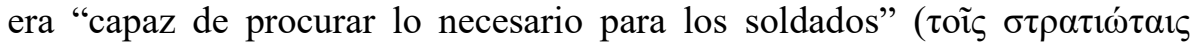

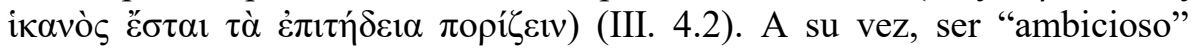

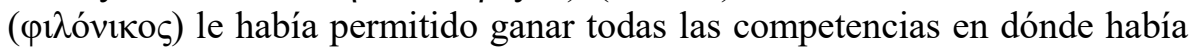
presentado a su coro, incluso sin tener ninguna experiencia de canto (III. 4. 3-4). ${ }^{12}$ Frente a la sorpresa de Nicomáquides, quien rechaza igualar las tareas de un general con las de un buen director de coro, Sócrates explicita a dónde se dirige con su argumento:

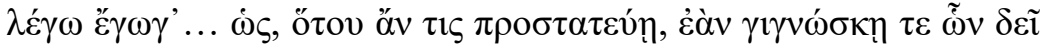

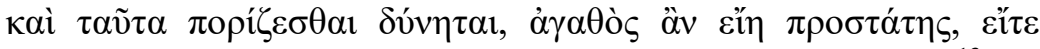

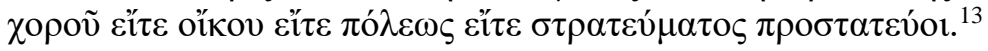

Yo por mi parte digo que, quien mande a cualquiera, si conoce lo que es necesario, y es capaz de proveerlo, será un buen líder, sea que lidere un coro, una hacienda, una ciudad o un ejército.

Y, en lo que es la consagración de esta estrategia "neutralizadora" a la que refiere Azoulay, Sócrates dice:

\footnotetext{
${ }^{11}$ Mem. III. 4. 1.

${ }^{12}$ Para un estudio sobre la philotimia y la philonikia en Jenofonte, ver ILlarRAGA (2020).

${ }^{13}$ Mem. III. 4. 6.

Stylos. 2021; 30 (30); pp. 18-35; ISSN: 0327-8859; E-ISSN: 2683-7900
} 


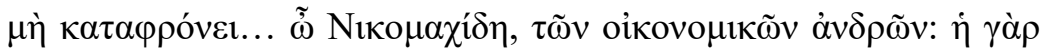

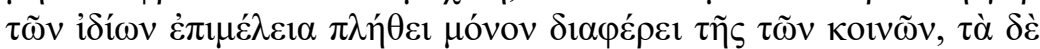
$\ddot{\alpha} \lambda \lambda \alpha \pi \alpha \rho \alpha \pi \lambda \eta \dot{\sigma} \sigma \alpha \alpha \ddot{\varepsilon} \chi \varepsilon{ }^{14}{ }^{14}$

Nicomáquides, no muestres desprecio por los administradores de haciendas, pues, el cuidado de los asuntos privados difiere de los públicos por su cantidad, pero son semejantes en el resto.

Podemos ver cómo en el cierre de este pasaje la dinámica de lo público y lo privado se termina por anclar en las redes de vinculación mencionadas anteriormente: la pólis y el oíkos, Aunque inmediatamente, la frontera entre ambas es relativizada por Jenofonte. En última instancia, si se trata de ponerse al frente de personas y mandarlas, no hay por qué interpretar a la pólis como un fenómeno social de carácter excepcional ni el ideal hacia el cual toda agrupación de individuos necesariamente deba tender. Por consiguiente, lo que vale para esta, vale también para el oíkos y viceversa. ${ }^{15}$

Tanto con el comienzo de Memorabilia, como también con la conversación entre Sócrates y Nicomáquides, hemos procurado mostrar dos cuestiones. En primer lugar, que la tensión entre lo público y lo privado es uno de los pilares que articula las Memorabilia de Jenofonte, al punto de que sobre ella se monta no solo la acusación a Sócrates, sino los argumentos esgrimidos para refutarla. En segundo lugar, que Jenofonte intentará mostrar cómo dicha tensión resulta intrascendente cuando es analizada desde ciertas perspectivas, puntualmente, el arte de mandar personas.

\section{5) LAS EMOCIONES DE CÁRMIDES ENTRE LA ASAMBLEA Y LAS REUNIONES PRIVADAS (MEM. III.7. 1-9)}

Sin abandonar el Libro III, arribamos finalmente al pasaje que describe el encuentro entre Cármides y Sócrates, el cual comienza de la siguiente forma:

\footnotetext{
${ }^{14}$ Mem. III. 4. 12.

${ }^{15}$ Sobre este punto, ver TAMIOLAKI (2009) y BARDI (2020).
} 


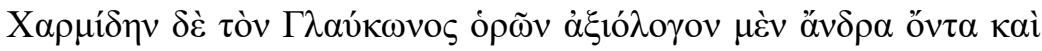

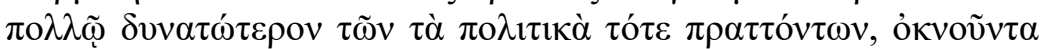

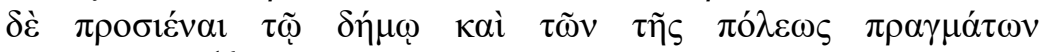
$\dot{\varepsilon} \pi \mu \varepsilon \lambda \varepsilon \varepsilon \tilde{\imath} \sigma \theta \alpha{ }^{16}$

Al ver que Cármides era un hombre digno de tenerse en cuenta y mucho más capaz que quienes entonces se dedicaban a la política, pero que no se atrevía a presentarse ante el pueblo y ocuparse de los asuntos de la ciudad...

En gran medida, la connotación y profundidad que adquirirá el resto del pasaje depende de la forma en la que interpretemos la expresión $\pi \rho 0 \sigma i \varepsilon ́ v \alpha \imath ~ \tau \tilde{̣}$ $\delta \eta ́ \mu \omega$, dado que es posible advertir dos niveles de sentido operando: uno que recupera el significado más "institucional" de démos, equivalente prácticamente a ekklesía, y que permitiría traducir por "presentarse ante la asamblea", y otro que recupera el significado netamente "poblacional", y que permitiría traducir por "presentarse ante el pueblo".

El riesgo en poner un énfasis tan marcado en este sentido más "institucional" de démos es que obtura una indagación sobre la causa de la reticencia de Cármides. Como veremos, el problema podrá explicarse a la luz de aquello que se pondría en juego en la aparición frente a los individuos que conforman el pueblo; es decir, a su elemento intersubjetivo. A su vez, la neutralidad de la palabra "asamblea" difumina la connotación anti-popular y oligárquica que empezará a adquirir el intercambio entre ambos interlocutores, lo cual es esperable dada la participación que Cármides habría de tener en el gobierno los Treinta Tiranos. Asimismo, para autores como Mogens Herman Hansen (2010: 506), en el uso que los filósofos, en especial socráticos, hacen de la palabra démos, siempre tiende a haber una fuerte carga negativa.

Al continuar con el diálogo, hay un detalle en la reacción de Cármides que resulta crucial en virtud del anterior análisis. Cuando Sócrates le comen-

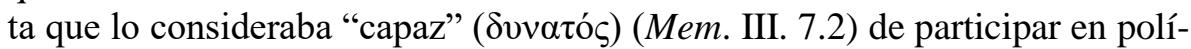
tica, el joven reacciona con total sorpresa. Desconoce cómo es que Sócrates

${ }^{16}$ Mem. III. 7. 1.

Stylos. 2021; 30 (30); pp. 18-35; ISSN: 0327-8859; E-ISSN: 2683-7900 
pudo haber llegado a dicha conclusión si él nunca había participado de la asamblea. Sorprendentemente, la opinión de Sócrates se fundaba:

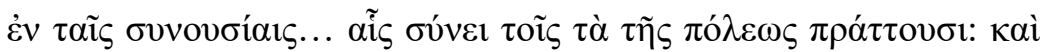

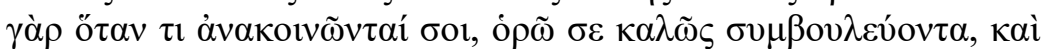

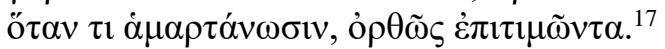

en las reuniones que tienes con los que manejan las cuestiones de la ciudad, pues cuando te comunican algún asunto veo que das buenos consejos, y cuando se equivocan en algo les hacer las correcciones adecuadas.

A lo que Cármides responde, apuntando al corazón de la teoría política jenofontea:

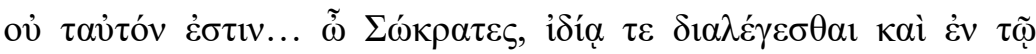
$\pi \lambda \dot{\eta} \theta \varepsilon \iota \dot{\alpha} \gamma \omega v i \zeta \zeta \varepsilon \sigma \theta \alpha{ }^{18}{ }^{18}$

Pero no es lo mismo, Sócrates, conversar en privado que discutir ante la multitud.

Posiblemente en este intercambio tenemos explicitado de una forma inmejorable las diferentes formas de concebir la relación entre la esfera privada y pública.

Por un lado, tenemos la postura socrática. Si seguimos la lectura de Azoulay, lo que estaría haciendo el Sócrates jenofonteo es llevar adelante aquel procedimiento que vimos en la conversación con Nicomáquides: "neutralizar" las diferencias entre ambas. Tornarla en una distinción irrelevante si lo que nos importa es el arte de mandar. De la misma forma que Antístenes, por ser un buen director de coros, tenía las capacidades necesarias para ser un buen estratego, Cármides, por haberse destacado en aquellas reuniones

${ }^{17}$ Mem. III. 7. 3.
${ }_{18}$ Mem. III. 7. 4.

Stylos. 2021; 30 (30); pp. 18-35; ISSN: 0327-8859; E-ISSN: 2683-7900 
privadas, tendría las capacidades necesarias para destacar en la Asamblea. Estamos frente a un claro paralelismo entre ambos personajes.

En la sorpresa de Cármides y su respuesta, vemos la otra perspectiva, la postura no-socrática, donde aquella distinción se muestra claramente diferenciada, al punto tal que ni siquiera el joven discípulo era capaz de hacer la asociación que tan linealmente marca el maestro. En esta posición, resulta inconcebible vincular la participación política y el ocuparse de los asuntos de la pólis a un ámbito rotulado como privado. Inclusive, la frontera es tan marcada que para Cármides a cada ámbito le corresponderán conductas opuestas, lo cual se evidencia en los verbos que Jenofonte elige: en el ámbito pri-

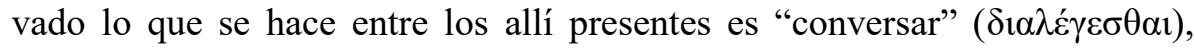
mientras que en la Asamblea, lo que se hace es "discutir" ( $\alpha \gamma \omega v i \zeta \varepsilon \sigma \theta \alpha l)$. En el primero se abre la puerta a un intercambio recíproco de opiniones, incluso a una dialéctica, mientras que en el segundo se remite al campo semántico de la competencia, y hasta de la abierta confrontación. A su vez, esto da cuenta de la explicitación de aquel sustrato anti-popular que mencionábamos, el cual se profundiza al reemplazarse el más ambiguo $\tau \tilde{\omega}$ $\delta \eta \dot{~} \mu$ por el peyorativo $\tau \tilde{\omega} \pi \lambda \dot{\eta} \theta \varepsilon$.

Pero lo destacable, y aquí la diferencia con otros pasajes de Memorabilia, es que luego de presentar estas formas opuestas de concebir la relación entre ambas esferas, Cármides va a incluir un componente emocional a la discusión, el cual utilizará para justificar su reticencia o autocensura a participar de la Asamblea.

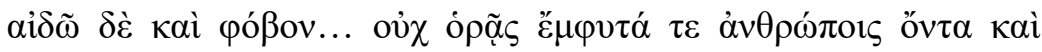

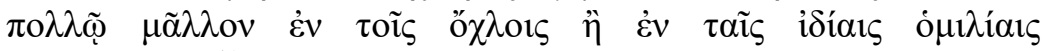
$\pi \alpha \rho \imath \sigma \tau \alpha \dot{\mu} \mu \varepsilon v \alpha ;{ }^{19}$

¿Es que no ves que la vergüenza y el miedo son innatos en las personas y les afectan mucho más ante las masas populares que en reuniones privadas?

\footnotetext{
${ }^{19}$ Mem. III. 7. 5.
}

Stylos. 2021; 30 (30); pp. 18-35; ISSN: 0327-8859; E-ISSN: 2683-7900 
Lo primero que podemos señalar de la postura de Cármides es que la "vergüenza" ( $\alpha i \delta \omega ́ \varsigma)$ y el "miedo" ( $\varphi$ ßo $\varsigma$ ) son emociones frente a las cuales el sujeto que las padece carecería de agencia para modificarlas, contentarlas o rechazarlas. El sujeto queda relegado a una pasividad emocional. Conectado a este aspecto pasivo, se advierte una reflexión en torno a su origen y su variabilidad según el contexto. Si su origen es "innato", "natural" o "inhe-

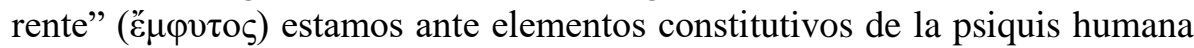
de los que el hombre no podría desembarazarse. Y por si esta falta de agencia fuera poca, su mayor o menor intensidad radica en condiciones externas, en este caso, el espacio en que dicha persona se encuentre.

Vinculando las temáticas planteadas hasta el momento, es posible advertir que, si bien ambas emociones, por ser innatas, necesariamente son comunes tanto a la esfera privada como a la pública, habría algo en la segunda que causaría un agravamiento de su padecimiento. Desde ya, la pregunta que irrumpe es la siguiente: ¿cuál es aquel elemento de la participación en la Asamblea que potenciaría las emociones de Cármides? ¿Se debe a la cantidad de espectadores, es decir, a una cuestión cuantitativa? ¿Se debe a la naturaleza de estos, es decir, una cuestión cualitativa? ¿O acaso la respuesta se encuentra en otro factor no tan explícito en la conversación?

Pero antes de decantarnos por alguna, vayamos a la respuesta de Sócrates y a su postura sobre las emociones de Cármides:

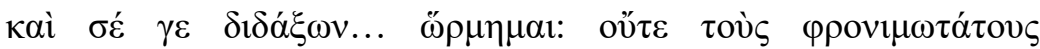

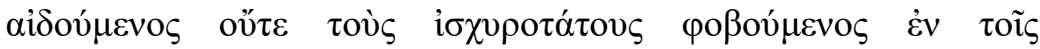

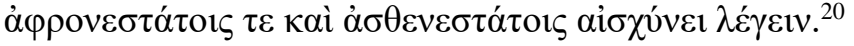

Estoy dispuesto a enseñarte a ti, que no te avergüenzas ante los más inteligentes ni sientes temor de los más fuertes, te da pudor hablar en presencia de los más insensatos y más débiles.

Entonces, contra la actitud de Cármides, para quien la vergüenza y el miedo estarían fuera del control o agencia del sujeto que las padece, ${ }^{21}$ Só-

${ }^{20}$ Mem. III. 7. 5.

Stylos. 2021; 30 (30); pp. 18-35; ISSN: 0327-8859; E-ISSN: 2683-7900 
crates abre la puerta a la posibilidad de operar sobre ellas. Y si bien nunca refuta la idea de que dichas emociones son innatas, esto no equivale a relegar al hombre a una completa pasividad emotiva: mediante la racionalización de la vergüenza y del miedo, y especialmente, de su vínculo con el contexto en el que emergen, Cármides sería capaz de abandonarlas. La vergüenza no tendría razón de ser cuando la mirada frente a cuál nos sentimos avergonzados es de alguien de menor jerarquía, en este caso, jerarquía intelectual. Con respecto al miedo, si bien aparece asociado a una jerarquía de "fuerza", en el contexto de la Asamblea este miedo adquiere una modalidad particular, no referido a un peligro físico, sino al ser objeto de risa, lo que terminaría por ubicarla muy cerca de la vergüenza.

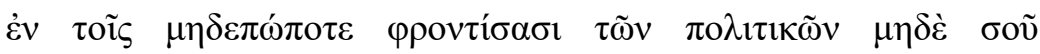

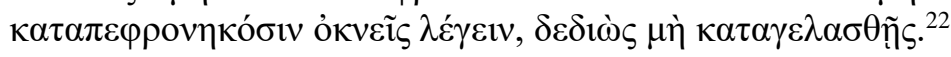

...dudas de hablar entre personas que nunca se han ocupado de política ni siquiera te han despreciado nunca, por temor a que se rían de ti.

Pero si volvemos a la pregunta que nos hicimos previamente e intentamos determinar qué es aquello que se ponía en juego para Cármides en la asamblea popular, más no en las reuniones privadas, tal que potenciara las emociones de la vergüenza y el miedo, advertiremos que esto nunca es profundizado. Sócrates no se propone indagar cuál era la causa que llevó a Cármides, en un primer momento, a sentir aquello que sentía. El correr el foco de la discusión hacia la baja calidad de los miembros de la asamblea solo estuvo al servicio de demostrar el error de la posición de Cármides, y en última instancia, de argumentar en favor de la "neutralización" de la diferencia entre la esfera pública y privada. Pero no hay un interés en proponer una $a i$ tiología de las emociones. Por ende, si lo que nos interesa es bosquejar una

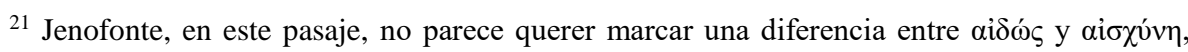
utilizándolas indistintamente. Para sus diferentes significados, ver CAIRNS (1993: 1-48).

${ }^{22}$ Mem. III. 7. 7.

Stylos. 2021; 30 (30); pp. 18-35; ISSN: 0327-8859; E-ISSN: 2683-7900 
explicación a dicha incógnita, debemos trascender la literalidad del texto jenofonteo.

\section{6) HANNAH ARENDT, EL "ESPACIO DE APARICIÓN" Y LAS EMOCIONES DE CÁRMIDES}

Para ello, el pensamiento de Hannah Arendt, y muchos de los conceptos por ella acuñados, nos sirven de auxilio. No resulta intrascendente que la clave de lectura propuesta por Azoulay guarde mucho en común con la forma en la que la filósofa alemana entendió en La Condición Humana la relación existente entre la esfera pública y privada en Atenas y el rol que la escuela socrática habría tenido en su reformulación teórica.

Su propuesta parte de enfatizar la infranqueable frontera que, a su parecer, existía entre la primera, asociada al ámbito espacial propio de la pólis, y la segunda, asociada al ámbito espacial propio del oíkos, al punto de sostener que estas se "excluían mutuamente" (ARENDT, 2020: 41). Citando a Werner Jaeger dirá que, a partir del advenimiento de la pólis: “... todo ciudadano pertenece a dos órdenes de existencia, y hay una tajante distinción entre lo que es suyo (ídion) y lo que es comunal (koinón)" (ARENDT, 2020: 39). Habrían sido los socráticos quienes sentaron las bases teóricas para el eventual borramiento de aquella frontera, por más que ninguno de ellos la abandonara totalmente, como lo expresa en el siguiente pasaje:

"La línea fronteriza entre familia y pólis queda a veces borrada, en especial en Platón, quien, probablemente siguiendo a Sócrates, comenzó a sacar su ejemplo e ilustraciones de la pólis mediante las experiencias cotidianas de la vida privada." (ARENDT, 2020: 48)

y lo remarca al sostener que:

"Estos aspectos de las enseñanzas de la escuela socrática... eran entonces los más nuevos y revolucionarios y surgían no de la experiencia real en la vida política, sino del deseo de liberarse de su carga, deseo que los filósofos sólo podían justificar en su propio

Stylos. 2021; 30 (30); pp. 18-35; ISSN: 0327-8859; E-ISSN: 2683-7900 
entendimiento demostrado que incluso la más libre de todas las formas de vida seguía relacionada y sujeta a la necesidad." (ARENDT, 2020: 48)

Hasta aquí, la incorporación de su pensamiento no parece agregar algo sustancialmente nuevo a los ejes que nos proveyó Azoulay para interpretar el pasaje jenofonteo. Pero si hay algo que nos aporta Arendt, aquello es una profunda reflexión sobre lo que en última instancia caracterizaba (y caracteriza) a la esfera pública y sobre lo que se ponía (y se pone) en juego en la participación política.

La esfera pública en Atenas creaba un "espacio de aparición", un ámbito en donde los individuos, al exponerse a la vista de sus pares ciudadanos y hablar frente a ellos, podían mostrar quienes eran, construir su identidad y lograr que sus actos dignos y virtuosos quedaran conservados en la memoria colectiva (ARENDT, 2020: 219). Estamos ante una reflexión fenomenológica de la participación política, con la particularidad de que se cimenta en una revalorización ontológica de aquello que "aparece". Así expresado, no resulta casual que muchos comentaristas de su obra hayan sostenido que el léxico arendtiano en torno a la participación política ateniense buscaba asimilarla a la performance teatral (CANOVAN, 1994: 189; EUBEN, 2000: 151).

Es preciso señalar que la imagen que Arendt construyó de la antigüedad clásica no está exenta de críticas. En especial, de aquellas que denuncian como forzado e inapropiado el intento de extender el marco teórico del existencialismo alemán a la comprensión el mencionado período histórico, sumado a un recorte parcial de los filósofos sobre los que trabaja (HINCHMAN \& HinchMAN, 1994: 144). Pero, si habría algo para cuestionar de la lectura arendtiana, no es tanto el haber realizado una interpretación anacrónica o incompleta de la antigüedad clásica sino, por el contrario, el intento de comprender la actualidad bajo categorías propias de la antigüedad: sería una suerte de anacronismo invertido, o al menos, una excesiva nostalgia helénica (O'SUlLIVAN, 1975: 228-251; STERNBERGER, 1977: 133; HINCHMAN \& HINCHMAN 1994: 163).

Dejando de lado los posibles cuestionamientos a su enfoque, la posibilidad de entender la esfera pública ateniense como un "espacio de aparición" estructurado a partir de los pilares de la visibilidad de los individuos, de la 
construcción de sus respectivas identidades y de la conformación de una memoria colectiva, nos abre un camino fértil para repensar los pasajes trabajados. Con estas herramientas conceptuales, el vínculo entre el comienzo de Memorabilia y el pasaje de Cármides se estrechan considerablemente. Recordemos que, para Jenofonte, si algo destacaba de la conducta de Sócrates era que pasaba la mayor parte del día en los espacios públicos de la pólis, los cuales se caracterizaban por potenciar las instancias de mostración y de intercambio con otros ciudadanos. Desde ya, esta descripción guarda armonía con la caracterización de los espacios presentados en el pasaje de Cármides, en donde las reuniones privadas son contrapuestas a la asamblea, capaz de posicionar al individuo que tomase la palabra en el grado máximo de visibilidad. De allí que las emociones de Cármides - la vergüenza y el miedo a manifestarse ante el pueblo- bien puedan estar fundadas en el hecho de que en aquel contexto se ponía en juego algo que en la esfera privada estaba totalmente ausente: la construcción de su identidad como ciudadano. Lo que Cármides hiciera y dijera en la asamblea quedaría grabado en la memoria colectiva de la pólis.

\section{7) REFERENCIAS BIBLIOGRÁFICAS}

Arendt, H. La Condición Humana, Buenos Aires: Paidós, 2020.

Azoulay, V. "Cyrus, disciple de Socrate? Public et privé dans l'œuvre de Xénophon", Études platoniciennes, 2009 6: 153-173.

BARDI, J. B. "La población en la reflexión jurídico-política de Jenofonte: el rol de los metecosatenienses en Póroi", Synthesis, 202027 (2), 1-13.

BEVILACQUA, F. Senofonte. Memorabili, Turín: UTET, 2010.

CAIRns, D. Aidos: The Psychology and Ethics of Honour and Shame in Ancient Greek Literature, Oxford: Clarendon Press, 1993.

Canovan, M. "Politics as Culture: Hannah Arendt and the Public Realm", 179 - 205. En HINCHMAN L. P. y HiNCHMAN S.K. (eds.) Hannah Arendt: critical essays, New York: SUNY Press, 1994.

Dorion, L. A. Xénophon. Mémorables, París: Les Belles Lettres, 2011. 
EubEN, P. “Arendt's Hellenism”, 151-164. En ViLla, D. (Ed.) The Cambridge Companion to Hannah Arendt, Cambridge: Cambridge University Press, 2000.

HANSEN, M. H. "The Concepts of Demos, Ekklesia, and Dikasterion in Classical Athens", Greek, Roman, and Byzantine Studies, 201050 (4).

HINCHMAN L. P. y HINCHMAN S.K. "Existentialism Politicized: Arendt's Debt to Jaspers", 143-178. En HinchMAn L. P. y HinCHMAN S.K. (eds.) Hannah Arendt: critical essays, New York: SUNY Press, 1994.

IllarragA, R. "Xenophon's Psychology of Philotimia", Greek, Roman, and Byzantine Studies, 202060 (2), 192-210.

Konstan, D. The Emotions of the Ancient Greeks Studies in Aristotle and Classical Literature, Toronto: University of Toronto Press, 2006.

Marchant, E. C., Xenophon. Xenophontis opera omnia, vol. 5. Oxford: Clarendon Press, 1920.

O'Sullivan, N. "Hellenic Nostalgia and Industrial Society" en De Crespigny, A., y Minogue, K., (eds.) Contemporary Political Philosophers, New York: Dodd, Mead and Company, 1975, 228-251.

Sternberger, D. "The Sunken City: Hannah Arendt's Idea of Politics", Social Research, 197744 (1),132-146.

TAMIOLAKI, M. "Public et privé dans le dialogue de Socrate avec Aristippe (Xén. Mém. II, 1, 1- 33)", Études platoniciennes, 2009 6, 141-151.

TAMIOLAKI, M. "Observaciones sobre la emoción y la persuasión en la Ciropedia de Jenofonte", Archai, 2021 31, 1-42.

Stylos. 2021; 30 (30); pp. 18-35; ISSN: 0327-8859; E-ISSN: 2683-7900 